\title{
Reversible GABAergic dysfunction involved in hippocampal hyperactivity predicts early- stage Alzheimer disease in a mouse model
}

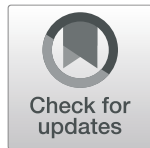

Yang $\mathrm{Li}^{1,2 \dagger}$, Ke Zhu ${ }^{1,3,4 \dagger}$, Ning $\mathrm{Li}^{1 \dagger}$, Xiaotong Wang ${ }^{1,3,4}$, Xuansheng Xiao ${ }^{1,3,4}$, Linying $\mathrm{Li}^{1,2}$, Lijuan $\mathrm{Li}^{1,3}$, Ying He ${ }^{1,3,4}$, Jinglan Zhang ${ }^{3}$, Jiaoyang $\mathrm{Wo}^{3}$, Yanqiu Cui ${ }^{3}$, Haixia Huang ${ }^{3}$, Jianliang Zhang ${ }^{1,4}$, Wei Wang ${ }^{3}$, Xiaomin Wang ${ }^{1,2,3^{*}}$ and Yan Zheng ${ }^{1,3,4^{*}}$ (D)

\begin{abstract}
Background: Neuronal hyperactivity related to $\beta$-amyloid $(A \beta)$ is considered an early warning sign of Alzheimer disease (AD). Although increasing evidence supports this opinion, the underlying mechanisms are still unknown.

Methods: Here, we recorded whole-cell synaptic currents and membrane potentials using patch clamping of acute hippocampal slices from human amyloid precursor protein (APP)/presenilin-1 transgenic (5XFAD) mice and their wild-type littermates. Biochemical methods, electron microscopic imaging, behavioral tests, and intraventricular drug delivery applied with osmotic pumps were used in this study.

Results: We confirmed hyperactivity of hippocampal CA1 pyramidal neurons in 5XFAD mice using whole-cell electrophysiological recording at 2.5 months old, when local A $\beta$-positive plaques had not developed and only mild cognitive dysfunction occurred. We further discovered attenuated inhibitory postsynaptic currents and unchanged excitatory postsynaptic currents in CA1 pyramidal neurons, in which the intrinsic excitability was unchanged. Moreover, the density of both $\gamma$-aminobutyric acid $A\left(G A B A_{A}\right)$ receptor subunits, a1 and $\gamma 2$, was reduced in synapses of the hippocampus in transgenic mice. Intriguingly, early intervention with the $G A B A_{A}$ receptor agonist gaboxadol reversed the hippocampal hyperactivity and modestly ameliorated cognitive performance in 5XFAD mice under our experimental conditions.
\end{abstract}

Conclusions: Inhibitory postsynaptic disruption critically contributes to abnormalities in the hippocampal network and cognition in 5XFAD mice and possibly in AD. Therefore, strengthening the GABAergic system could be a promising therapy for AD in the early stages.

Keywords: Neuronal hyperactivity, Synaptic transmission, Alzheimer's disease, GABA receptors, 5XFAD mouse

\footnotetext{
* Correspondence: xmwang@ccmu.edu.cn; zhengyan@ccmu.edu.cn

${ }^{\dagger}$ Yang Li, Ke Zhu and Ning Li contributed equally to this work.

'Key Laboratory for Neurodegenerative Disorders of the Ministry of Education, Capital Medical University, Beijing 100069, China

Full list of author information is available at the end of the article
}

(c) The Author(s). 2021 Open Access This article is licensed under a Creative Commons Attribution 4.0 International License, which permits use, sharing, adaptation, distribution and reproduction in any medium or format, as long as you give appropriate credit to the original author(s) and the source, provide a link to the Creative Commons licence, and indicate if changes were made. The images or other third party material in this article are included in the article's Creative Commons licence, unless indicated otherwise in a credit line to the material. If material is not included in the article's Creative Commons licence and your intended use is not permitted by statutory regulation or exceeds the permitted use, you will need to obtain permission directly from the copyright holder. To view a copy of this licence, visit http://creativecommons.org/licenses/by/4.0/ The Creative Commons Public Domain Dedication waiver (http://creativecommons.org/publicdomain/zero/1.0/) applies to the data made available in this article, unless otherwise stated in a credit line to the data. 


\section{Background}

Alzheimer disease (AD) is a common cause of dementia that features extracellular $\beta$-amyloid $(\mathrm{A} \beta)$ deposition and intracellular neurofibrillary tangles [1] and has a pathogenesis that is not clearly understood. Although overproduction or accumulation of $A \beta$, which is generated from its precursor protein (APP), is considered to have a leading role in $\mathrm{AD}$ pathophysiology [2], most clinical trials targeting this mechanism have failed, indicating that the mechanisms in the early stages of AD need further exploration.

The optimal function of a neural circuit is dependent on the effective information processing of individual synapses. The ensemble of excitatory and inhibitory inputs to postsynaptic action potential (AP) conversion determines specialized circuit functions during cognitive processes. The hippocampus is responsible for computing contextual and spatiotemporal information and is an indispensable brain region for learning and memory processes. An imbalance of the inhibitory and excitatory synaptic inputs in the hippocampus results in disrupted AP outputs, mainly from pyramidal neurons [3-5], which play a key role in computing various signals in learning behaviors. Derangement of the neural circuitry and subsequent epileptiform activity in the hippocampus is considered a critical event involved in $\mathrm{AD}$ [6-9].

Although functional synaptic failure and related neural circuit aberrance in some regions of the brain in AD are widely accepted as critical events in the whole process of AD [10-14], the exact mechanism underlying this network aberrance has yet to be elucidated. It has been assumed that hippocampal neuronal hyperactivity associated with epileptic seizures is a very early functional impairment, is even a surrogate marker in patients with AD and animal models, and occurs before extracellular $A \beta$ deposition $[9,15-18]$. Yet, how presynaptic or postsynaptic components contribute to neuronal hyperactivity and ultimate neural network disintegration and cognitive disorder in AD is poorly understood.

Our previous observations and other studies have revealed attenuated excitatory synaptic transmission [19], a decline in long-term potentiation [20], and abnormal neuronal activity $[21,22]$ in the brains of the 5XFAD mouse model carrying human mutations of APP/presenilin-1 (PS1). However, the early phenotypes related to $\mathrm{AD}$ pathology and the mechanism involved in brain region-specific neuronal hyperactivity in $\mathrm{AD}$ remain to be clarified. In the present study, we sought to explore the mechanism involved in hippocampal neuronal hyperactivity that is correlated with cognitive deficits in early disease stages in an AD mouse model. First, we confirmed that hyperactivity of pyramidal neurons in CA1 preceded A $\beta$-related pathology and was accompanied by mild cognitive impairments in 5XFAD transgenic mice. Further investigation revealed that the aberrant AP output from CA1 pyramidal neurons was driven by $\gamma$-aminobutyric acid $A\left(G_{A B A}\right)$ receptor-mediated inhibitory synaptic decline. Most importantly, $\mathrm{GABA}_{\mathrm{A}}$ receptor agonist could reverse the decline in cognitive performance in the mouse model. Thus, we propose that functional decline in inhibitory synaptic transmission critically contributes to hippocampus hyperactivity and cognitive deficits in the early stages of AD-like conditions. Therefore, activating $\mathrm{GABA}_{\mathrm{A}}$ receptors could be a promising path to early intervention of $\mathrm{AD}$.

\section{Methods}

Animal model and brain slices recordings

APP/PS1 (5XFAD) double transgenic mice (006554, Jackson Laboratory) carrying human APP and PS1 transgenes containing five FAD mutations (APPSwFlLon, PSEN1*M146L"L286V) under the transcriptional control of the neuron-specific mouse Thy-1 promoter were bred in strict accordance with Chinese regulations involving animal protection. The animal experiment was approved by the animal ethics committee of Capital Medical University. Mice were maintained by crossing heterozygous transgenic mice with C57BL/6 wild-type breeders. We used female heterozygous mice in electrophysiological recordings and male heterozygous in behavioral tests, aged between 2.5 and 3.5 months, and non-transgenic wild-type age-matched littermates served as the control group.

Under chloral hydrate (I.P. $300 \mathrm{mg} / \mathrm{kg}$ ) anesthesia, mice were transcardially perfused with cutting solution, and the brains were immediately removed and cut with a vibratome (Leica, VT1200S). For cell recordings, the slices were placed in a recording chamber constantly perfused with ACSF (Supplementary Information).

\section{Subcellular fractionation}

Shared with the above electrophysiological experiment when needed. Fractions were prepared as described previously with a few modifications (Supplementary Information).

\section{Western blotting}

Equal amounts of proteins, which were quantified with BCA protein assay kit (23225, Pierce TM) from WT and FAD fractions were subjected to $10 \%$ SDS-polyacrylamide gels and transferred to nitrocellulose membranes. Then, the membranes were incubated with various primary antibodies (Supplementary Information).

\section{ELISA}

The mouse brain tissues were homogenized in cold RIPA buffer. The supernatant and the pellet were separated for soluble and insoluble $A \beta$ detections, 
respectively, with kits (KHB3441, KHB3481, Invitrogen) (Supplementary Information).

\section{Biocytin labeling and immunostaining}

Neuronal morphology and spine density of CA1 neurons were determined by adding biocytin $(0.04 \%)$ in the pipette solution during whole-cell recording. Specific antibodies recognizing subunits of $\mathrm{GABA}_{\mathrm{A}}$ receptors or AMPA receptors were used in immunofluorescent detection. Avidin-biotin complex $(\mathrm{ABC})$ staining was used to determine $A \beta$-positive signals (Supplementary Information).

\section{Electron microscopic imaging}

Brain tissues were punched and subjected to sequential preparation for imaging of transmission electron microscope (HITACHI, JAPAN, HT7700) (Supplementary Information).

\section{Behavior and drug treatment}

Paradigms of contextual fear conditioning (CFC) and episodic-like memory were utilized to estimate hippocampus-dependent cognition of mice. For drug treatment in vivo, intraventricular delivery was performed to mimic local perfusion as applied in slice recording (Supplementary Information).

\section{Statistical analysis}

All data were first tested for normality. Datasets that passed the normality test were subjected to parametric tests with unpaired t-test for two groups comparison or one/two-way ANOVA for more than two groups comparison. The data which did not pass the normality test were analyzed by non-parametric tests. The analysis software was GraphPad Prism 8.0.1 (detailed statistical reports can be found in Supplementary Table 1).

\section{Results}

CA1 neuronal hyperactivity preceded local $A \beta$ deposition and was accompanied by mild cognitive decline in 5XFAD mice

We first examined the phenotypical characteristics of WT and 5XFAD mice. The CFC was applied to differentiate hippocampus-dependent contextual fear memory, showing significant attenuated performance in 5XFAD mice at the age of 4.5 months compared with their WT littermates. At 2.5 months old, although the 5XFAD mice had no significant change in freezing percentage on average, these mice varied individually (Fig. 1A, B), indicating differing stages of disease progression. Interestingly, in episodic-like memory tests (Fig. 1C), although at 5.5 months old the transgenic mice showed considerable impairment in discrimination between familiar and novel objects (Fig. 1D), at 2.5 months old, they spent more time in contact with familiar objects than with novel ones, in contrast to WT controls (Fig. 1D). This result may reflect mild symptoms of $\mathrm{AD}$ in which recent memory reflects early memory impairment in the AD process [23]. Furthermore, we used an index of displaced familiar objects vs. stationary familiar objects to evaluate cognition with contextual information. The 5XFAD mice at 5.5 months old showed an impaired ability to discriminate stationary object $A$, which carried "old" information in association with episodiclike memory (Fig. 1E, 5.5 mon). Intriguingly, despite showing non-significance compared with WT control mice, all transgenic mice at 2.5 months old had no ability to recognize the stationary object A (Fig. 1E, 2.5 mon). These results imply that hippocampal functions would have been damaged at 2.5 months of age in the 5XFAD mice. In addition, the 5XFAD mice at 2.5-3.5 months old exhibited a dramatic increase in insoluble $A \beta$ (Supplementary Figure 1), but we barely observed accumulation of $A \beta$ in the hippocampal CA1 region, despite intracellular and extracellular deposition in the subiculum (Fig. 1F), which is an output region of CA1.

At ages 2.5-3 months, male 5XFAD mice showed a pathological phenotype that was comparable with that of female 5XFAD mice. We therefore performed physiological experiments using female mice and tested behaviors using male mice to avoid possible effects of the menstrual cycle in the present study. To evaluate the firing state of CA1 pyramidal neurons in the mice, we prepared acute hippocampal slices and recorded the spontaneous action potential (sAP) with a whole-cell current clamp. The frequency of sAP in the CA1 pyramidal neurons of 5XFAD mice at 2.5 months old was moderately enhanced compared with WT mice $(\mathrm{p}=$ 0.038; Fig. 1G, H) while becoming more pronounced with advancing age (Supplementary Figure 2). Considering that the resting membrane potential (Fig. 1I), amplitude of the action potential (AP) spike (Fig. 1J), and halfwidth of the AP (Fig. 1K) were unchanged, these two genotypic mice have the same basic physiologic firing properties. In a neuron, a higher input resistance may result in the depolarization threshold in the AP being easily reached. Therefore, we measured input resistance by applying subthreshold step-current injections with a duration of $500 \mathrm{~ms}$, and rheobase with brief step-current injections with a duration of $3 \mathrm{~ms}$ sequentially. Consistently, both the input resistance and the rheobase of CA1 pyramidal neurons in 5XFAD mice were comparable with that of WT mice (Fig. 1L, M). These results confirmed that neuronal hyperactivity in the hippocampal CA1 precedes local extracellular $A \beta$ accumulation in the AD mouse model. In addition, the intrinsic neuronal excitability was unchanged by the APP/PS1 transgenic background at this age, suggesting synaptic dysfunction 


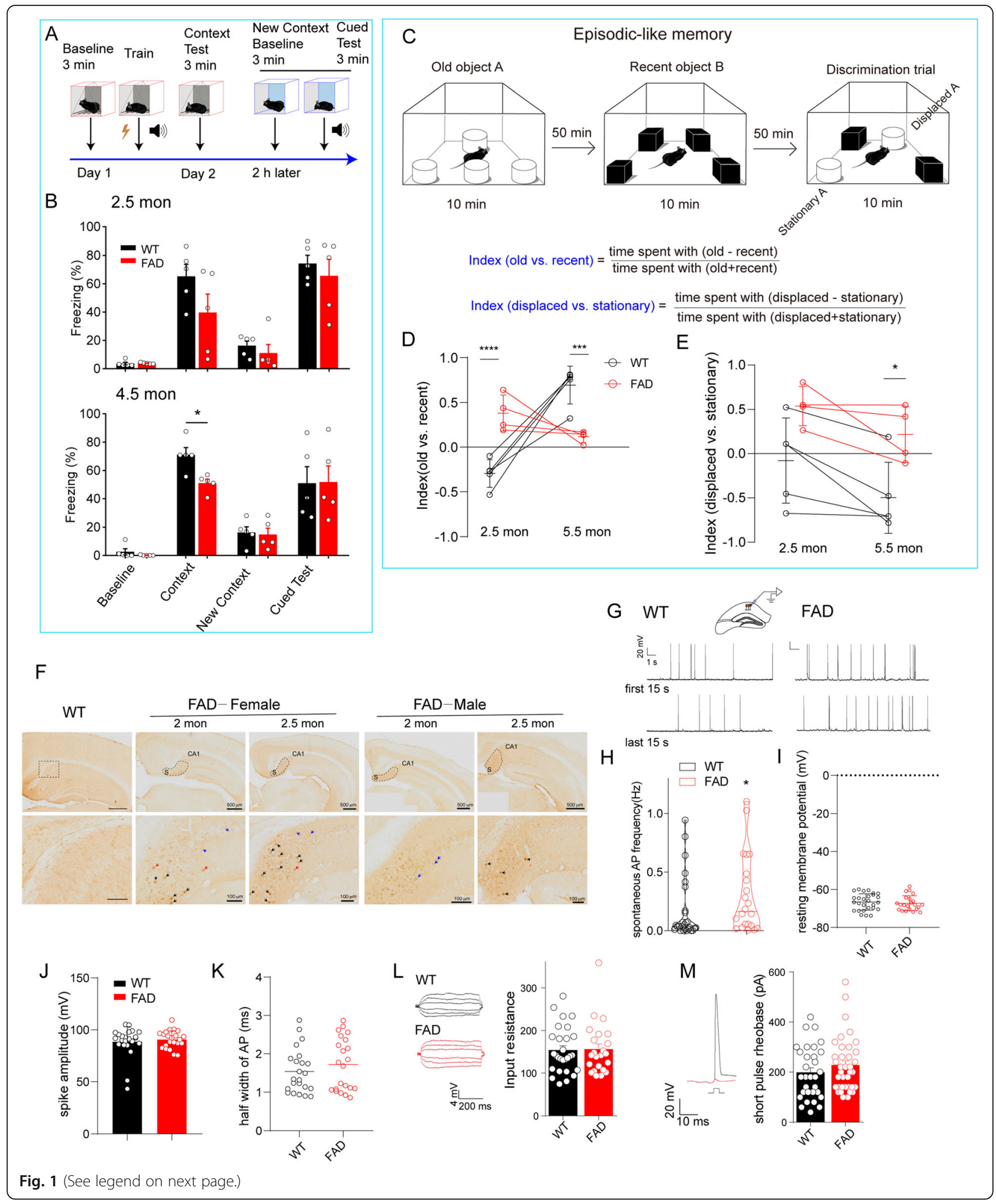


(See figure on previous page.)

Fig. 1 Hippocampal CA1 pyramidal neurons exhibited hyperactivity accompanied with few extracellular A $\beta$ plaques in 5XFAD mice with mild cognitive decline. A Schematic diagram of contextual fear conditioning (CFC). B 5XFAD mice showed a significant reduction in freezing time at 4.5 months old ( $51.08 \pm 2.76 \%$ vs. $71.14 \pm 5.052 \%)$ while remained comparable level with WT mice at 2.5 months old $(39.62 \pm 29.4 \%$ vs. $65.19 \pm$ 18.88\%) in context test. Data are analyzed by two-way ANOVA with Bonferroni's multiple comparisons test, mean \pm SEM, ${ }^{*} p<0.05$ vs. WT, $n=5$ mice per group. C novel object recognition paradigm reflecting episodic-like memory. D, E The index (old vs. recent) indicating the ability to identify objects (D) and the index (displaced vs. stationary) indicating episodic memory of mouse (E) were subjected to statistical analysis. ${ }^{*} p<$ $0.05,{ }^{* *} p<0.001,{ }^{* * *} p<0.0001$ vs. WT with two-way ANOVA, followed by Sidak's multiple comparisons test, $n=5$ in WT, $n=4$ in FAD. Interaction (age $\times$ genotype) is significant (*** $p=0.0002$ ) in $\mathbf{D}$ and not significant in $\mathbf{E}$. $\mathbf{F}$ Intraneuronal A 3 (stained with 6 E10 antibody) signals were found in the cortex and hippocampus. The subiculum areas were surrounded by dashed lines (above), bar scale $500 \mu \mathrm{m}$. Obvious $A \beta$ deposition was shown in a locally enlarged image of the subiculum (bottom) in a 2-2.5-month-old 5XFAD mouse. Red arrow: primary plaques; black arrow: canonical plaques; blue arrow: intraneuronal A $\mathrm{B}$ deposition. Bar scale $100 \mu \mathrm{m}$. G Action potential of the CA1 pyramidal neuron in WT (left) or 5XFAD mice (right) (female at 2.5 months old) was recorded with whole-cell current-clamp recording. The traces show the first $15 \mathrm{~s}$ and the last $15 \mathrm{~s}$ in at least 5 min recording time. $\mathbf{H}-\mathbf{K}$ The spontaneous action potential (SAP) events during recording time $(\mathbf{H})$, the resting membrane potential (I), the amplitude of spike $(\mathbf{J})$, and the half-width of AP were detected automatically with Clampfit10.4. Unpaired Student's ttest was used to compare these two groups, and the Mann-Whitney test was used in $\mathbf{H}^{*}{ }^{*} p=0.0380, n=27$ neurons/13 mice for WT; $n=22$ neurons/10 mice for FAD, effect size is 0.299. In $\mathbf{J}$ and $\mathbf{K}$, unpaired t-test with Welch's correction was applied. Except for $\mathbf{H}$, all values are presented as mean \pm SEM. L Subthreshold stimulation was constituted of current injections from -30 to $+30 \mathrm{pA}$ in a duration of $500 \mathrm{~ms}$, and the input resistance of CA1 pyramidal neurons in WT and 5XFAD mice was determined by Ohm's law. $\mathbf{M}$ Step current injections (increment 10 pA) crossing the threshold were performed to determine the short-pulse rheobase of neurons. The red trace indicates the last subthreshold voltage response, and the black trace depicts the first firing triggered by suprathreshold current injection. The dots indicate individual neurons recorded, $n=28$ (FAD), $n=23$ (WT) in $\mathbf{L} ; n=31(\mathrm{WT}), \mathrm{n}=37$ (FAD) in $\mathbf{M}$. Unpaired Student's t-test was used in $\mathbf{L}$ and $\mathbf{M}$

underlying CA1 neuronal hyperactivity in the early stage of AD pathophysiology.

\section{Activity-dependent excitatory synaptic transmission to CA1 pyramidal neurons of 5XFAD mice was unchanged} As the intrinsic properties of CA1 pyramidal neurons were not altered, we determined whether inhibitory or excitatory synaptic transmission to CA1 pyramidal neurons contributed to the hyperactivity in the transgenic hippocampus. We first measured mEPSCs in CA1 pyramidal whole-cell recordings. The slight increases in amplitude and frequency of mEPSCs of CA1 pyramidal neurons in 5XFAD slices (Fig. 2A-C), together with the cumulative distribution of these currents that had shifted to higher amplitude or frequency of mEPSC events compared with that of WT slices (Fig. 2D, E), indicated little enhanced spontaneous excitatory synaptic transmission. As the miniature synaptic events were recorded in the presence of TTX, which blocked activity-dependent synaptic transmission, we further recorded evoked AMPA receptor-mediated EPSCs (AMPAR-EPSCs) at the holding potential of $-60 \mathrm{mV}$, responding to incremental stimulus intensities applied at Schaffer collateral. In contrast to the changes in miniature events, as stimulus intensity increased, CA1 pyramidal neurons in the 5XFAD brain slices showed a decreasing trend, but with no statistical change in AMPAR EPSC amplitude (Fig. 2F, G). The paired-pulse ratios (PPRs) at multiple interstimulus intervals (Fig. $2 \mathrm{H}$ ), that is, inversely correlated with presynaptic transmitter release probability [24], were also not affected. The result of the activity-dependent synaptic responses suggested that the basic excitatory synaptic transmission to CA1 pyramidal neurons can be assumed to be compensatory in early stages of the AD-like process. To determine whether the dendritic morphology of CA1 pyramidal neurons was changed, we included biocytin in the intracellular recording pipette during whole-cell recording and performed observations with confocal microscopy (Fig. 2I). The 5XFAD neurons showed dendrite spine density and surface area comparable to those of WT neurons (Fig. 2J), supporting our hypothesis that the enhancement of miniature excitatory synaptic events was a secondary and functional response of CA1 neurons in the $\mathrm{AD}$ context. Observations by electron microscopy revealed supportive evidence that the number of asymmetric synapses, the cleft width of synapses, and the length and width of postsynaptic density were all intact in the transgenic mouse hippocampus (Fig. 2K-O).

\section{Inhibitory synaptic transmission to CA1 pyramidal neurons was attenuated in the brain of 5XFAD mice} In contrast to mEPSCs, the mIPSCs of FAD CA1 pyramidal neurons displayed a decrease in amplitude and a slight increase in frequency as compared with WT neurons (Fig. 3A-C). The cumulative distribution of mIPSCs in 5XFAD neurons consistently displayed a shift to lower amplitude or higher frequency (Fig. 3D, E). This result suggested that inhibitory synaptic transmission is probably damaged in early stages of the AD-like process. To further determine activity-dependent inhibitory synaptic transmission, we recorded evoked $\mathrm{GABA}_{\mathrm{A}}$ receptor-mediated IPSC (eIPSC) current using electrostimulation at Schaffer collateral in the absence of TTX, with QX314 in a pipette to block the voltage-gated sodium channel in the recorded cell. As expected, we observed a suppressed response to higher stimulus intensities $(80-100 \mu \mathrm{A})$ and a pronounced reduction in 


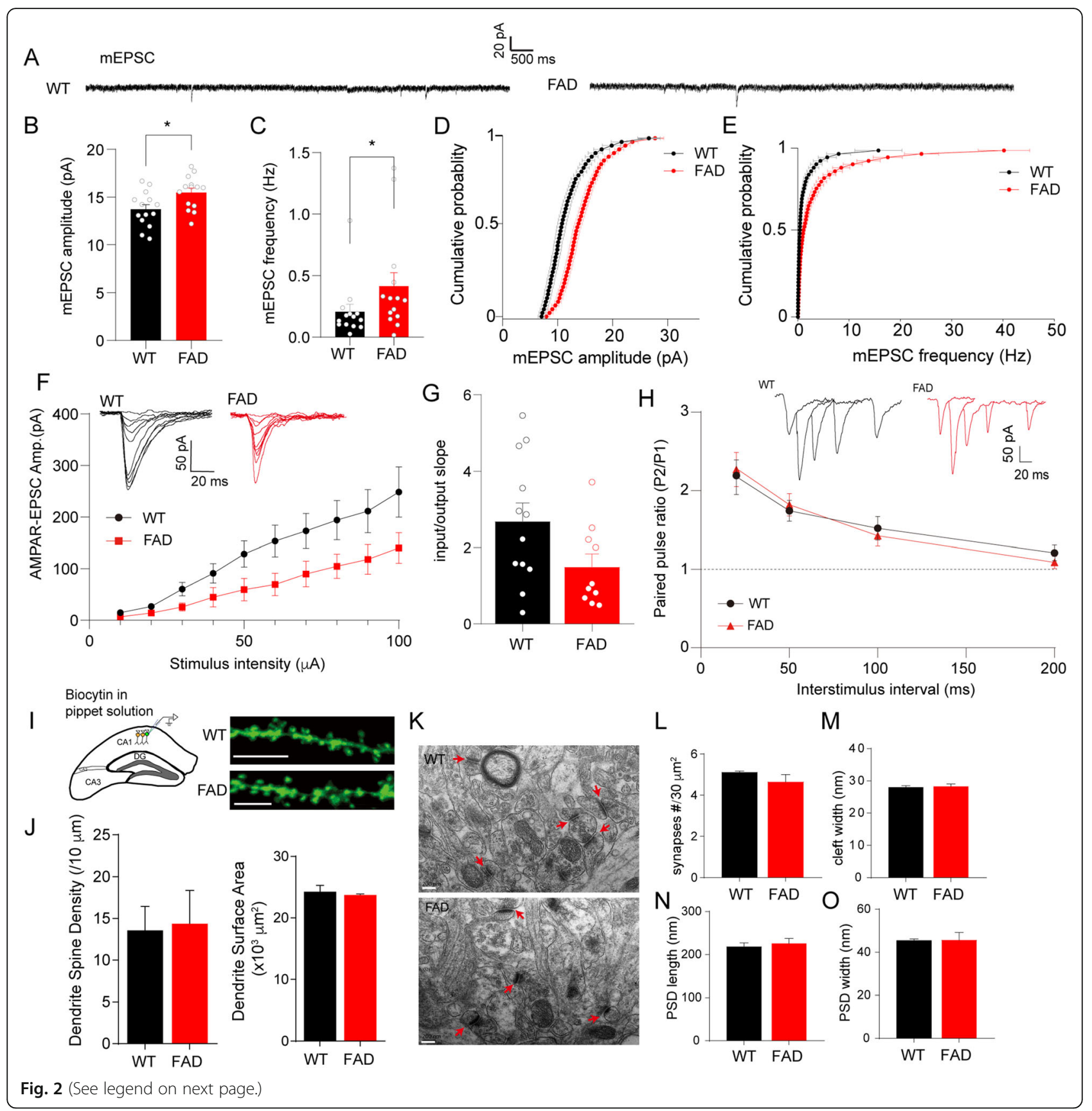




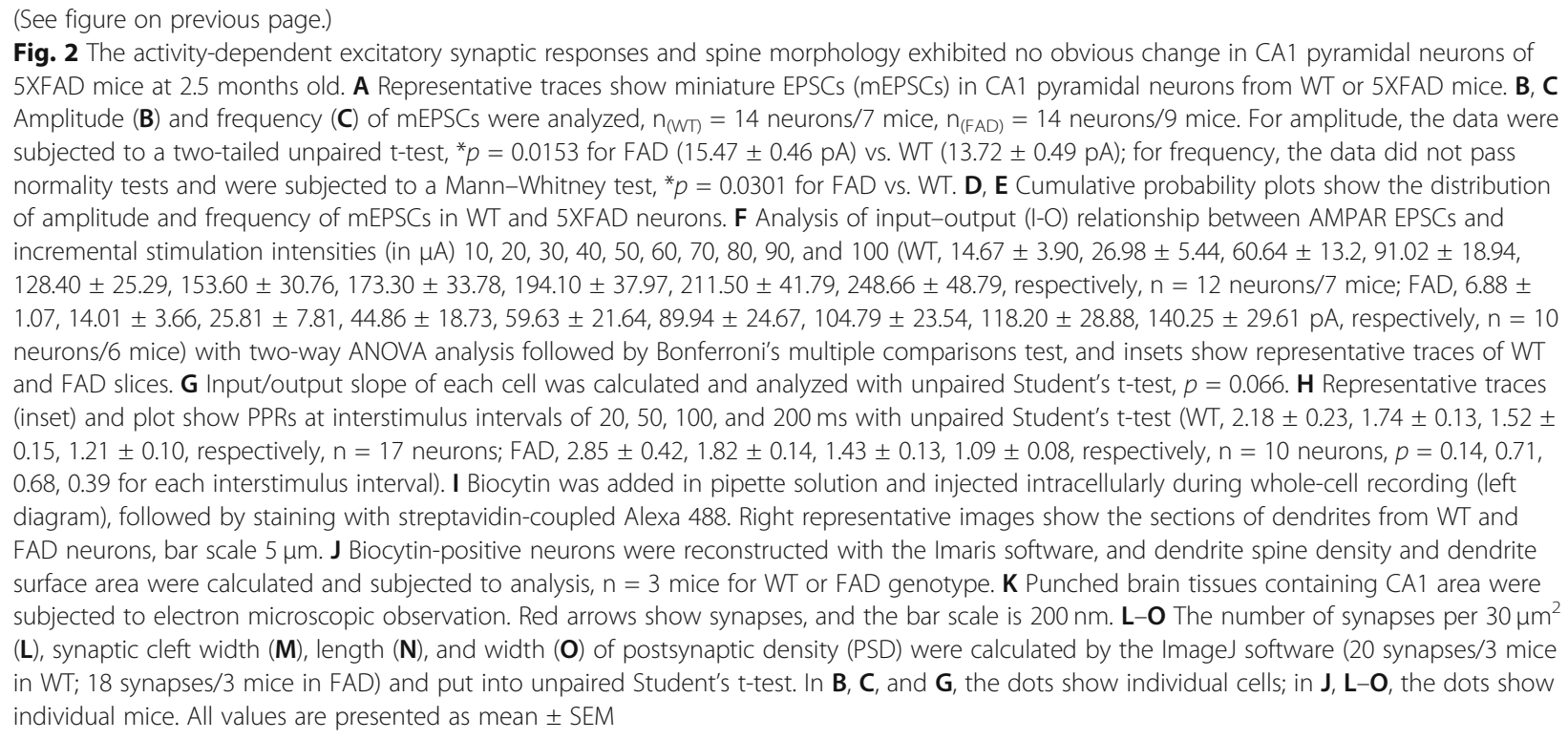

the input/output slope of eIPSCs in 5XFAD slice neurons compared with WT neurons (Fig. 3F, G). Given that the response of the postsynaptic membrane can be attributed to either a presynaptic release probability or function of postsynaptic receptors, we checked the PPRs of eIPSCs in these neurons. Notably, the 5XFAD neurons had higher PPRs than those of WT neurons (Fig. 3H), indicating decreased activity-dependent presynaptic GABA release onto 5XFAD CA1 pyramidal neurons. As $\mathrm{GABA}_{\mathrm{A}}$ receptors mediate IPSCs, we also conducted immunofluorescent imaging of $\mathrm{GABA}_{\mathrm{A}}$ receptor subunit $\alpha 1$. Intriguingly, $\alpha 1$ expression displayed a regional selective decrease in the stratum lacunosum-moleculare (SLM) of CA1, with a normal level of MAP2 expression in the 5XFAD brain (Fig. 3I, J). Given that the SLM is a subfield, the apical dendrites of the CA1 pyramidal neurons are located in and accept direct inputs from the entorhinal cortex [25], which is one of the earliest involved regions of the brain in $\mathrm{AD}$ [1]. Our result implies that the integration of inhibitory synaptic transmission in CA1 would most likely be damaged by the early $\mathrm{AD}$ related microenvironment.

$\mathrm{GABA}_{\mathrm{A}}$ receptors can mediate either phasic synaptic transmission or tonic inhibition via activation of extrasynaptic $\mathrm{GABA}_{\mathrm{A}}$ receptors caused by GABA release from reactive astrocytes owing to $\mathrm{AD}$ pathology [26, 27]. Therefore, we recorded tonic current induced by the $\mathrm{GABA}_{\mathrm{A}}$ blocker bicuculline in the presence of GABA and GABA uptake inhibitor. We found that the $A D$ transgenic background neither increased the degree of the tonic response of CA1 pyramidal neuron nor affected the astrocytic immunoreactivity (Supplementary Figure 3).
$\mathrm{GABA}_{\mathrm{A}}$ receptor sensitivity to agonist was reduced, accompanied by decreased subunit density in the synapses in the hippocampus of 5XFAD mice

We next asked whether the decreased inhibitory synaptic transmission was due to a decrease in the total level of these receptors or only their altered distribution in the synapses. To answer this question, we separated the synapses from total hippocampal extracts of 2.5-monthold 5XFAD and WT mice. The distribution of $\mathrm{GABA}_{\mathrm{A}} \mathrm{R}$ $\alpha 1$ in both cytosolic fractions (P1) and membraneassociated fractions (P2) in 5XFAD hippocampal synapses was significantly reduced, with normal total protein levels, as compared with WT mice (Fig. 4A-C). Because $\alpha 1 / \beta / \gamma 2$ containing heteropentameric $\mathrm{GABA}_{\mathrm{A}}$ receptors are predominantly located in brain synapses $[28,29]$, we also examined the $\gamma 2$ subunit expression, which showed an obvious reduction in cytosolic fractions but had normal levels of membrane fractions compared with WT mice (Fig. 4D). In the same experimental system, AMPA Rs subunits, GluA1 and GluA2, exhibited normal levels of cytosolic and membrane fractions, except for a lower membrane fraction level in GluA1 than that of WT mice (Fig. 4E, F). However, we found no obvious change in GluA1 immunostaining in the hippocampus of 5XFAD mice (Supplementary Figure 4). These findings indicated that the $\mathrm{GABA}_{\mathrm{A}}$ receptors displayed a decline in synaptic distribution, with a normal reserve pool, and probably maintained repairable synaptic function. Therefore, we added a $\mathrm{GABA}_{\mathrm{A}}$ receptor agonist, GBX in ACSF, to treat current-clamped neurons and observed a retarded response of 5XFAD neurons in discharging change (after 4 min of perfusion with ACSF-containing GBX); WT neuron displayed a fast drop in firing frequency after 2 min of GBX treatment (Fig. 4G). Despite the delayed 


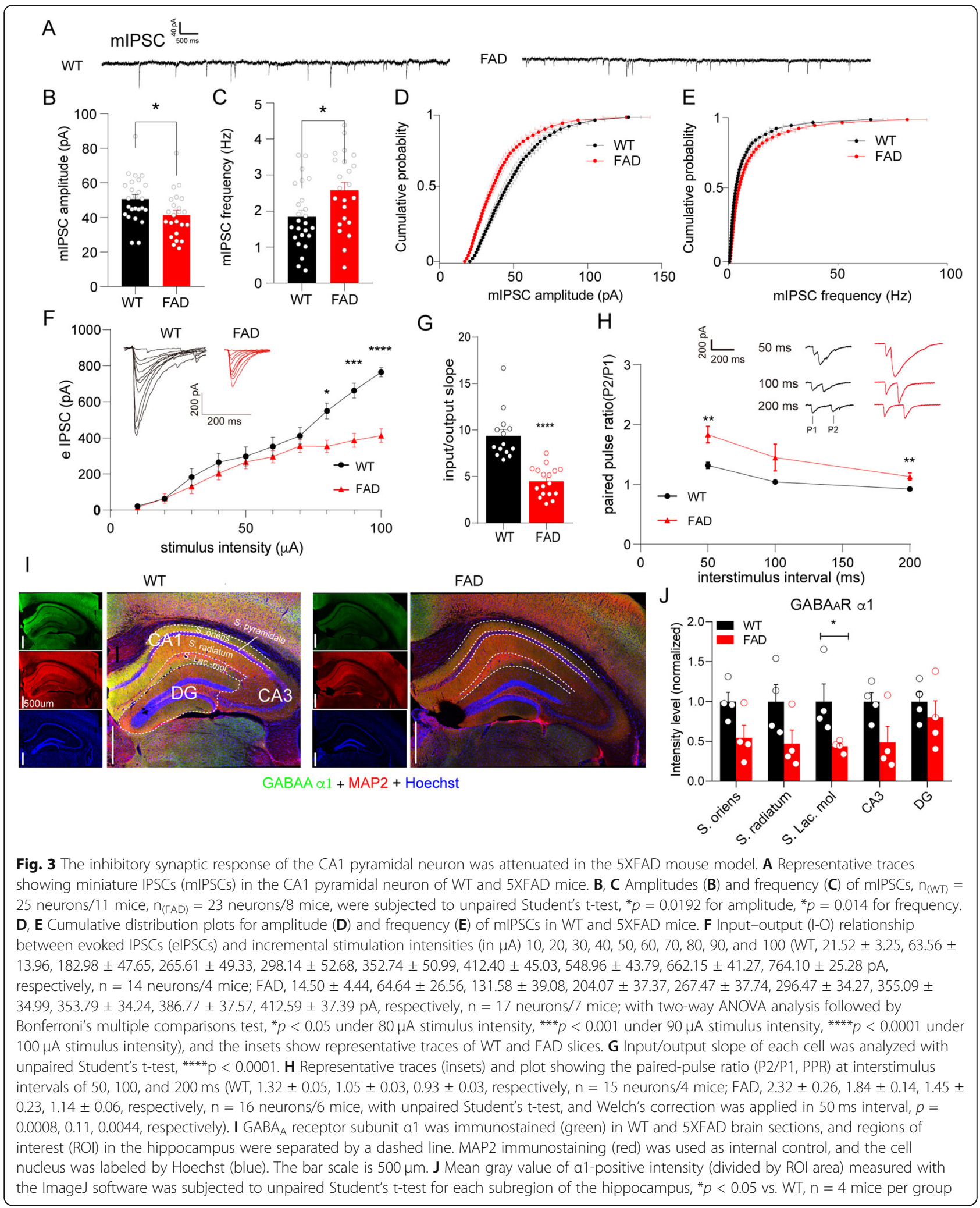




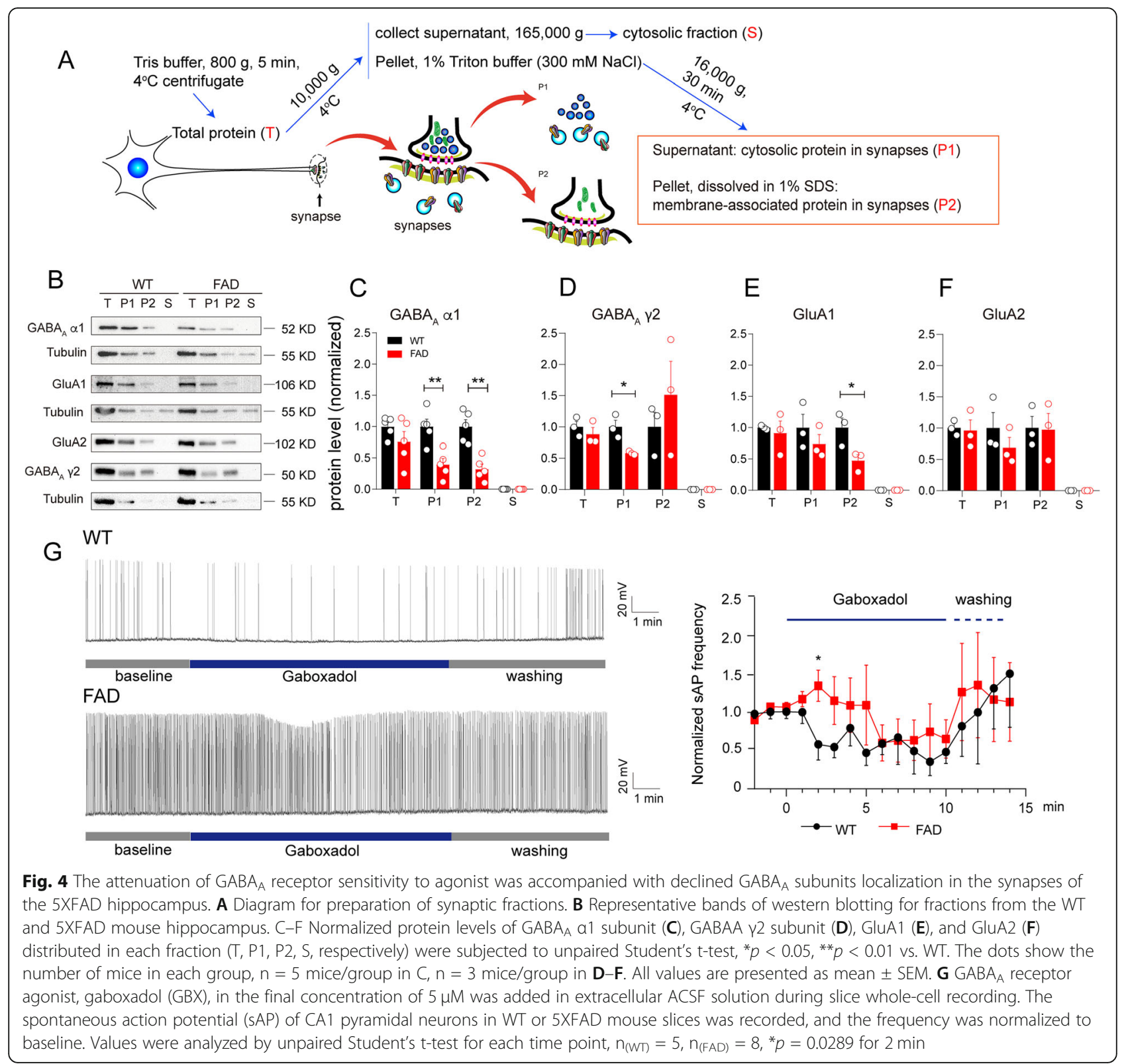

response to GBX, 5XFAD abnormal firing was eventually repressed by the $G_{A B A}$ agonist, suggesting on the one hand that the functional decline in $\mathrm{GABA}_{\mathrm{A}}$ receptors may play a key role in CA1 neuronal hyperactivity and, on the other hand, that $\mathrm{AD}$-like phenotypes in the early stages could be intervened using $\mathrm{GABA}_{\mathrm{A}}$ receptor agonists.

\section{Activating $\mathrm{GABA}_{\mathrm{A}}$ receptors modestly ameliorated cognitive performance in SXFAD mice}

We further asked if the functional decline in inhibitory synaptic transmission was specifically a critical causative event in $\mathrm{AD}$ progression and whether activating the $\mathrm{GABA}_{\mathrm{A}}$ receptors could rescue cognitive behaviors in the AD model in the early stages. Thus, we treated 5XFAD mice at 3.5 months old with GBX, which is a metabolically stable $\mathrm{GABA}_{\mathrm{A}}$ receptor agonist that has been used in the treatment of sleep order [30], or with saline to evaluate cognitive performance in CFC and episodic-like memory tasks. We used osmotic pumps to deliver the drug in local concentrations of $5 \mu \mathrm{M}$, which is equal to that used in slice perfusion, at a speed of $0.25 \mu \mathrm{L} / \mathrm{h}$ to provide continuous unilateral intraventricular drug treatment; the treatment lasted for 28 days (Fig. 5A). Under these conditions, the hippocampus should be the main area receiving the drug effect. In the CFC test, there was no significant difference in the percent of freezing time in the context trial between GBX- 


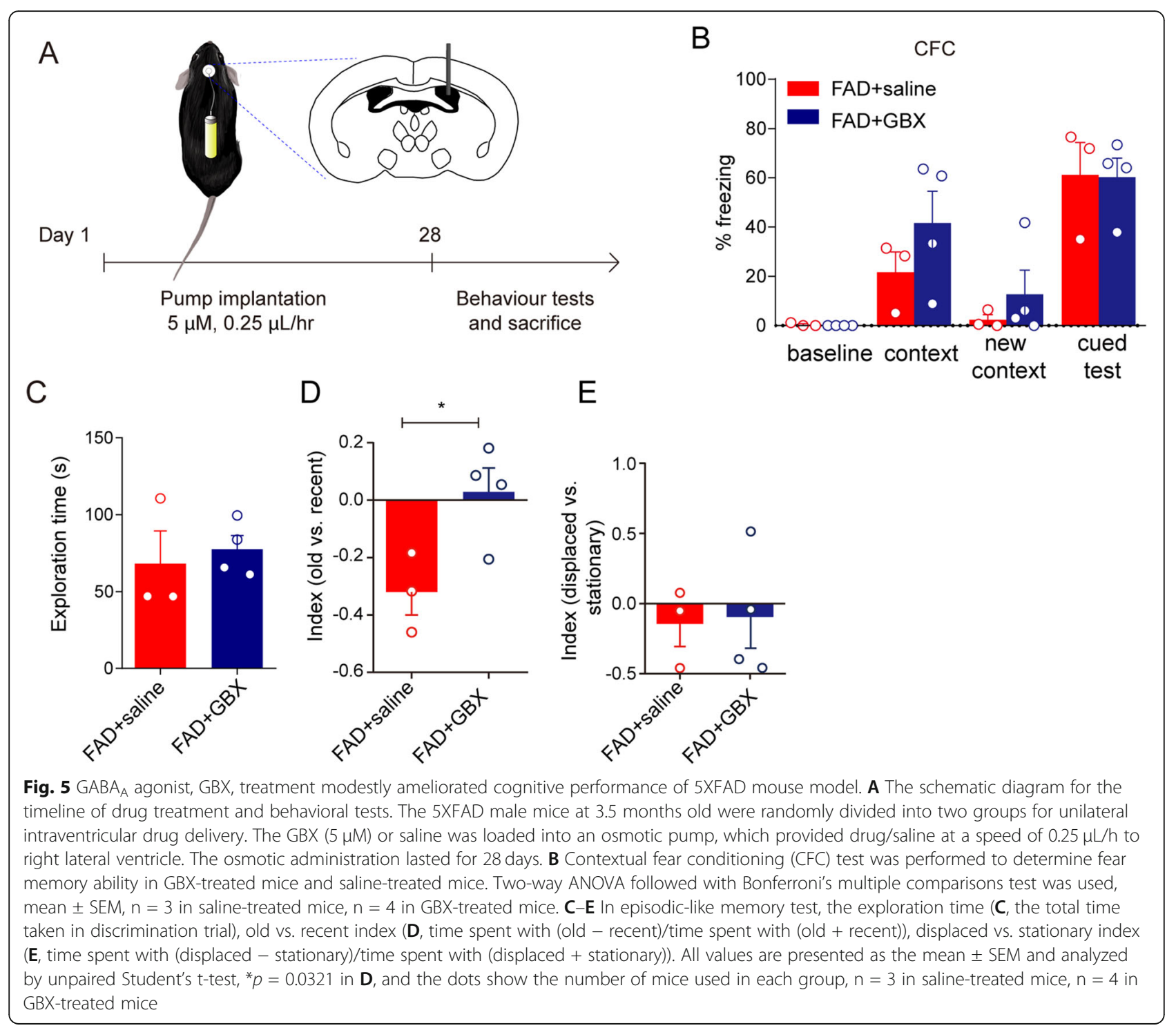

treated 5XFAD mice and saline-treated 5XFAD mice (Fig. 5B, $41.64 \pm 12.89 \%$ vs. $21.67 \pm 8.31 \%$ ). However, with a comparable exploration time to the saline-treated 5XFAD mice (Fig. 5C), the GBX-treated 5XFAD mice displayed better recognition of familiar objects (Fig. 5D, $p=0.0321$; raw data in Supplementary Table 2). Unexpectedly, the GBX treatment had no effect on the displaced vs. stationary index, which carries contextual information (Fig. 5E), implying that the intervention time point should be set earlier.

\section{Discussion}

Neuronal hyperactivity is considered an early warning sign of $\mathrm{AD}[6,8,17,31]$. A $\beta$-related excitotoxicity [32] and calcium overload [18,33] are reportedly involved in this aberrant neuronal activity. Here, we confirmed that CA1 pyramidal neuronal hyperactivity preceded local extracellular $A \beta$ deposition in the 5XFAD mouse hippocampus, with early AD-like behavioral deficits. Furthermore, the decline in the inhibitory synaptic transmission, rather than the excitatory synaptic transmission and intrinsic properties of the CA1 pyramidal neurons, contributed to aberrant neuronal activation in the early stages of the $\mathrm{AD}$ model. The decrease in $\mathrm{GABA}_{\mathrm{A}}$ receptor localization in hippocampal synapses and the related diminished synaptic response mainly contributed to $A \beta$-associated hyperactivity (Supplementary Figure 6). Most importantly, memory impairment in the 5XFAD mouse model was partially reversed by $\mathrm{GABA}_{\mathrm{A}}$ strengthening in vivo. Thus, we propose a novel opinion that functional decline in inhibitory synaptic transmission due to reduced postsynaptic localization of $\mathrm{GABA}_{\mathrm{A}}$ receptors plays a causative role in 
hippocampal hyperactivity and ensuing cognitive deficits in the $\mathrm{AD}$ process.

We previously found that hippocampus-dependent cognitive ability in the 5XFAD mouse model declined at 4 months of age with the commonly used protocol of the Morris water maze [34, 35]. However, the ability of reversal learning and memory, as well as LTP expression in the hippocampus, declined in the 5XFAD mice compared with their WT littermates as early as $2-3$ months old [20], when little extracellular A $\beta$ deposition had developed [34] (Fig. 1F), indicating that synaptic dysfunction associated with early cognitive impairment was a forerunner in the $\mathrm{AD}$ process.

Accumulating evidence shows that the dendritic structure is altered in the hippocampal neurons of patients with AD and in animal models [12, 36, 37]. Neuronal hyperexcitability in the 5XFAD mouse hippocampus has been attributed to dendritic structural degeneration [22]. Although CA1 neuronal hyperactivity was confirmed in our study (Fig. 1), we did not find obvious changes in dendritic morphology (Fig. 2), suggesting that functional events rather than structural alterations contribute to the early stages of $\mathrm{AD}$. In consideration of our discovery of unaltered intrinsic excitability of CA1 pyramidal neurons (Fig. 1), we propose that synaptic dysfunction is the real culprit in neuronal hyperactivity occurring during the early stage of $\mathrm{AD}$.

Although we cannot exclude the possibility that CA1 neuronal hyperactivity was initiated by suppression of glutamate reuptake [32], we did not find obvious changes in activity-dependent excitatory synaptic transmission to CA1 pyramidal neurons (Fig. 2). Clinical evidence has shown that tissues isolated from the temporal cortices in the brain of patients with AD display a loss of GABA receptor subunits, $\alpha 1$ and $\gamma 2$ [38]. In agreement with that study, a decrease in amplitude of IPSCs was observed in hippocampal CA1 pyramidal neurons of the 5XFAD model (Fig. 3), with a small increase in amplitude and frequency of mEPSCs but without pronounced changes in AMPAR EPSCs (Fig. 2). This finding strengthens our proposal that inhibitory inputs to CA1 neurons could be an early dysfunctional event in the $\mathrm{AD}$ pathological context. Interestingly, the PPRs revealed an activity-dependent reduction in the inhibitory presynaptic release probability (Fig. $3 \mathrm{H}$ ), contradicting the increased mIPSC frequency (Fig. 3C), which suggested an enhancement in the spontaneous presynaptic release. The data support an opinion of compensatory remodeling of inhibitory hippocampal circuits, as proposed by Palop et al., although those authors observed an increase in the amplitude of mIPSCs in the dentate gyrus of another AD mouse model [7].

Presynaptic $\mathrm{GABA}_{\mathrm{B}}$ receptor 1a can bind to SAPP $\alpha$, which is generated by $\alpha$-secretase proteolysis of APP, to regulate presynaptic transmitter release [39], or it can interact with APP to stabilize it at the cell surface and thereby reduce $A \beta$ production [40]. Therefore, the decreased activity-dependent presynaptic release probability may be attributed to AD-related mechanisms, e.g., amyloidogenic APP processing, although the mechanism needs further study. Intriguingly, the $\mathrm{GABA}_{\mathrm{A}} \alpha 1$ distributed in the SLM of the hippocampus was selectively reduced (Fig. 3), with suppressed synaptic fractions and unchanged total protein levels in all hippocampal tissues (Fig. 4). Given that the SLM receives projections from the entorhinal cortex [25], which is the key area involved in early $\mathrm{AD}$ pathology [1], we suggest that the aberrant activity of CA1 pyramidal neurons in the early stage of $\mathrm{AD}$ may be partially attributed to dysfunction of the entorhinal cortex-CA1 circuit. Nevertheless, how the trisynaptic circuit entorhinal cortex-CA3-CA1 integrates with the direct circuit entorhinal cortex-CA1 should be carefully investigated in future work.

Considering the presynaptic mechanisms, inhibitory interneurons in CA1 local circuits may contribute to network dysfunction under AD conditions, as dysfunction of parvalbumin-positive inhibitory interneurons [3, 41] and oriens-lacunosum-moleculare (O-LM) inhibitory interneuron [42] has been found to be involved in memory impairment in amyloidosis AD models. Importantly, Schmid et al. [42] revealed the axon loss of O-LM interneurons in the CA1 SLM due to a reduction of acetylcholine from septo-hippocampal projections, which supports our finding of decreased PPR of IPSC in CA1 pyramidal neurons (Fig. 3H). Nevertheless, how inhibitory interneurons interact with pyramidal neurons to regulate CA1 local circuits requires further study using a double-patch recording system. Another interesting study demonstrated that $\mathrm{A} \beta$ treatment can specifically reduce inhibitory transmission at the dendritic synapses [43], which supports our hypothesis that $A \beta$-induced abnormal integration of inhibitory synapses in CA1 pyramidal neurons plays a leading role in the $\mathrm{AD}$ process.

Although loss of $\mathrm{GABA}_{\mathrm{A}}$ receptors and inhibitory synaptic dysfunction associated with $\mathrm{AD}$ has been previously discussed [38, 44-46], there is no uniform understanding of whether inhibitory synaptic transmission to CA1 pyramidal neurons is altered and involved in the early stage of $\mathrm{AD}$. The $\alpha 1$ subunit-containing $\mathrm{GABA}_{\mathrm{A}}$ receptors are mainly located on the postsynaptic membrane and mediate phasic inhibition in the brain [29]. Our finding of a loss of function of $\mathrm{GABA}_{\mathrm{A}}$ receptors in the 5XFAD hippocampus was consistent with clinical evidence that AD patient-derived cell membranes displayed a reduction in GABA-mediated currents [38]. In addition, we found decreased localization of the $\mathrm{GABA}_{\mathrm{A}} \alpha 1$ subunit in the synaptic membrane but with a normal reserve pool in the hippocampus of 
5XFAD mice. Hence, an early therapeutic window during which neuronal activity would be remodeled is proposed. As expected, the $\mathrm{GABA}_{\mathrm{A}}$ agonist GBX eventually suppressed the neuronal hyperactivity (Fig. 4) and partially prevented cognitive decline (Fig. 5) in the 5XFAD mouse, corroborating that functional impairment in the GABAergic system makes a major contribution to a cognitive abnormality in $\mathrm{AD}$ and can be a target for early treatment.

GBX is a hypnotic drug that has been reported to act on extrasynaptic $\mathrm{GABA}_{\mathrm{A}}$ receptors to drive tonic inhibition in the neocortex [30], thalamus, and dentate gyrus [47]. Here, we suggest that inhibitory synaptic transmission is strengthened by GBX, although we cannot rule out the possible contribution of extrasynaptic $G_{A B A}$ receptor-mediated conductance in this process. Nevertheless, we found no changes in the tonic inhibitory current of CA1 neurons nor in reactive astrocytes (Supplementary Fig. 3), which is reportedly related to local A $\beta$ accumulation in the 5XFAD brain $[26,27]$. Notably, a recent study reported that systemic administration of GBX rescued the tau-induced adult hippocampal neurogenesis deficits and improved contextual cognition in AD mice [46]. Together, this evidence suggests that strengthening the GABAergic system would be effective in both the $A \beta$-related and tau-related courses of AD.

\section{Limitations}

Here, we did not apply systemic treatment in the AD mouse model because we sought to first confirm the direct effect of strengthening $\mathrm{GABA}_{\mathrm{A}}$ receptors on the abnormal hippocampal network in vivo. Therefore, further studies should be performed to explore a method of $\mathrm{AD}$ treatment targeting the GABAergic system that is safe, less toxic, and highly effective.

\section{Conclusions}

In recent years, the fact that many preclinical studies focusing on $A \beta$ have been ineffective has pushed researchers in this field to seek more effective and promising strategies to cure or even prevent $\mathrm{AD}$. Our study suggests that GABAergic remodeling may be a useful path to re-orchestration of the hippocampal network in the early stage of $\mathrm{AD}$, although the following open questions remain to be answered. How does $\mathrm{GABA}_{\mathrm{A}}$ agonist regulate postsynaptic receptor redistribution? How is the possible interaction of intracellular $A \beta$ and $G_{A B A}$ receptors involved in the $A D$ process? Can activation of $\mathrm{GABA}_{\mathrm{A}}$ receptors restore functions of the cognitive network in the early stage of human $\mathrm{AD}$ ?

\section{Abbreviations}

AB: $\beta$-Amyloid; AD: Alzheimer's disease; AMPAR: a-Amino-3-hydroxy-5methylisoxazole-4-propionic acid receptor; AP: Action potential; APP: Amyloid precursor protein; BACE1: $\beta$-Site amyloid precursor protein cleaving enzyme
1; EPSC: Excitatory postsynaptic current; FAD: Familial Alzheimer's disease; GABA: Y-Aminobutyric acid; GABA : $\gamma$-Aminobutyric acid A; GBX: Gaboxadol; IPSC: Inhibitory postsynaptic current; mIPSC: Miniature inhibitory postsynaptic current; mEPSC: Miniature excitatory postsynaptic current; NMDAR: N-methylD-aspartate receptor; PPR: Paired-pulse ratio; PV: Parvalbumin; SAP: Spontaneous action potential; SDS: Sodium dodecyl sulfate; SLM: S. lacunosum-moleculare; TTX: Tetrodotoxin

\section{Supplementary Information}

The online version contains supplementary material available at https://doi. org/10.1186/s13195-021-00859-8.

\section{Additional file 1: Supporting Information. \\ Additional file 2: Supplementary Table S1. \\ Additional file 3: Supplementary Table S2.}

\section{Acknowledgements}

We thank Hui Yang, Hua Li, and Hua Wei from Capital Medical University, China, for their technical support. We thank Dr. Zhen Yan (State University of New York at Buffalo) for her valuable suggestions.

\section{Authors' contributions}

Biochemical, behavioral, and pharmacological tests were performed by Yang $\mathrm{Li}$ and Xuansheng Xiao, Physiological data were recorded by Ke Zhu, Ning Li, Xiaotong Wang; and Xuansheng Xiao, and the other co-authors performed the quality control and statistical analysis in double-blind for behavioral and electrophysiological data. Yan Zheng designed the study and wrote the manuscript with the help of all other authors. Xiaomin Wang supervised the study. All authors read and approved the final manuscript.

\section{Funding}

This work was supported by the National Natural Science Foundation of China $(81971004,81571038,81771145$ to YZ), Beijing Natural Science Foundation (5202006 to YZ), and the National Key Research and Development Program of China (2016YFC1306300 to XMW).

\section{Availability of data and materials}

The datasets used and/or analyzed during this study are available from the corresponding author on reasonable request.

\section{Declarations}

Ethics approval and consent to participate

Not applicable.

\section{Consent for publication \\ Not applicable.}

\section{Competing interests}

The authors declare that they have no competing interests.

\section{Author details}

'Key Laboratory for Neurodegenerative Disorders of the Ministry of Education, Capital Medical University, Beijing 100069, China. ${ }^{2}$ Beijing Institute for Brain Disorders, Capital Medical University, Beijing 100069, China.

${ }^{3}$ Department of Physiology and Pathophysiology, School of Basic Medical Sciences, Beijing, China. ${ }^{4}$ Beijing Key Laboratory of Neural Regeneration and Repair, Beijing, China.

Received: 28 January 2021 Accepted: 3 June 2021

Published online: 14 June 2021

\section{References}

1. Thal DR, Rub U, Orantes M, Braak H. Phases of Aß-deposition in the human brain and its relevance for the development of AD. Neurology. 2002;58(12): 1791-800. https://doi.org/10.1212/WNL.58.12.1791.

2. Selkoe DJ, Hardy J. The amyloid hypothesis of Alzheimer's disease at 25 years. EMBO Mol Med. 2016;8(6):595-608. https://doi.org/10.15252/emmm.2 01606210. 
3. Verret L, Mann EO, Hang GB, Barth AM, Cobos I, Ho K, et al. Inhibitory interneuron deficit links altered network activity and cognitive dysfunction in Alzheimer model. Cell. 2012;149(3):708-21. https://doi.org/10.1016/j.cell.2 012.02 .046$.

4. Sohal VS, Zhang F, Yizhar O, Deisseroth K. Parvalbumin neurons and gamma rhythms enhance cortical circuit performance. Nature. 2009:459(7247):698702. https://doi.org/10.1038/nature07991.

5. Cardin JA, Carlen M, Meletis K, Knoblich U, Zhang F, Deisseroth K, et al. Driving fast-spiking cells induces gamma rhythm and controls sensory responses. Nature. 2009;459(7247):663-7. https://doi.org/10.1038/nature08002.

6. Dickerson BC, Salat DH, Greve DN, Chua EF, Rand-Giovannetti E, Rentz DM, et al. Increased hippocampal activation in mild cognitive impairment compared to normal aging and AD. Neurology. 2005;65(3):404-11. https:// doi.org/10.1212/01.wnl.0000171450.97464.49

7. Palop JJ, Chin J, Roberson ED, Wang J, Thwin MT, Bien-Ly N, et al. Aberrant excitatory neuronal activity and compensatory remodeling of inhibitory hippocampal circuits in mouse models of Alzheimer's disease. Neuron. 2007; 55(5):697-711. https://doi.org/10.1016/j.neuron.2007.07.025.

8. Vossel KA, Tartaglia MC, Nygaard HB, Zeman AZ, Miller BL. Epileptic activity in Alzheimer's disease: causes and clinical relevance. Lancet Neurol. 2017; 16(4):311-22. https://doi.org/10.1016/S1474-4422(17)30044-3.

9. Palop JJ, Mucke L. Amyloid-beta-induced neuronal dysfunction in Alzheimer's disease: from synapses toward neural networks. Nat Neurosci. 2010;13(7):812-8. https://doi.org/10.1038/nn.2583.

10. Hardy J, Selkoe DJ. The amyloid hypothesis of Alzheimer's disease: progress and problems on the road to therapeutics. Science. 2002;297(5580):353-6. https://doi.org/10.1126/science.1072994

11. Walsh DM, Klyubin I, Fadeeva JV, Cullen WK, Anwyl R, Wolfe MS, et al. Naturally secreted oligomers of amyloid beta protein potently inhibit hippocampal long-term potentiation in vivo. Nature. 2002;416(6880):535-9. https://doi.org/10.1038/416535a.

12. Grutzendler J, Helmin K, Tsai J, Gan WB. Various dendritic abnormalities are associated with fibrillar amyloid deposits in Alzheimer's disease. Ann N Y Acad Sci. 2007;1097(1):30-9. https://doi.org/10.1196/annals.1379.003.

13. Sheng M, Sabatini BL, Sudhof TC. Synapses and Alzheimer's disease. Cold Spring Harb Perspect Biol. 2012;4(5). https://doi.org/10.1101/cshperspect.a 005777

14. Shankar GM, Li S, Mehta TH, Garcia-Munoz A, Shepardson NE, Smith I, et al. Amyloid- $\beta$ protein dimers isolated directly from Alzheimer's brains impair synaptic plasticity and memory. Nat Med. 2008;14(8):837-42. https://doi. org/10.1038/nm1782

15. Busche MA, Konnerth A. Impairments of neural circuit function in Alzheimer's disease. Philos Trans R Soc Lond B Biol Sci. 2016;371. https://doi. org/10.1098/rstb.2015.0429.

16. Hsia AY, Masliah E, McConlogue L, Yu GQ, Tatsuno G, Hu K, et al. Plaqueindependent disruption of neural circuits in Alzheimer's disease mouse models. Proc Natl Acad Sci U S A. 1999;96(6):3228-33. https://doi.org/10.1 073/pnas.96.6.3228.

17. Sperling RA, Laviolette PS, O'Keefe K, O'Brien J, Rentz DM, Pihlajamaki M, et al. Amyloid deposition is associated with impaired default network function in older persons without dementia. Neuron. 2009;63(2):178-88. https://doi.org/10.1016/j.neuron.2009.07.003.

18. Busche MA, Chen X, Henning HA, Reichwald J, Staufenbiel M, Sakmann B, et al. Critical role of soluble amyloid- $\beta$ for early hippocampal hyperactivity in a mouse model of Alzheimer's disease. Proc Natl Acad Sci U S A. 2012; 109(22):8740-5. https://doi.org/10.1073/pnas.1206171109.

19. Zheng Y, Liu A, Wang ZJ, Cao Q, Wang W, Lin L, et al. Inhibition of EHMT1/2 rescues synaptic and cognitive functions for Alzheimer's disease. Brain. 2019; 142(3):787-807. https://doi.org/10.1093/brain/awy354.

20. Li N, Li Y, Li L, Zhu K, Zheng Y, Wang XM. Glutamate receptor delocalization in postsynaptic membrane and reduced hippocampal synaptic plasticity in the early stage of Alzheimer's disease. Neural Regen Res. 2019;14(6):1037-45. https://doi.org/10.4103/1673-5374.250625.

21. laccarino HF, Singer AC, Martorell AJ, Rudenko A, Gao F, Gillingham TZ, et al. Gamma frequency entrainment attenuates amyloid load and modifies microglia. Nature. 2016;540(7632):230-5. https://doi.org/10.1038/nature2 0587.

22. Siskova Z, Justus D, Kaneko H, Friedrichs D, Henneberg N, Beutel T, et al. Dendritic structural degeneration is functionally linked to cellular hyperexcitability in a mouse model of Alzheimer's disease. Neuron. 2014; 84(5):1023-33. https://doi.org/10.1016/j.neuron.2014.10.024.
23. Jagust W. Imaging the evolution and pathophysiology of Alzheimer disease. Nat Rev Neurosci. 2018;19(11):687-700. https://doi.org/10.1038/s41583-0180067-3.

24. Polepalli JS, Wu H, Goswami D, Halpern CH, Sudhof TC, Malenka RC. Modulation of excitation on parvalbumin interneurons by neuroligin-3 regulates the hippocampal network. Nat Neurosci. 2017;20(2):219-29. https://doi.org/10.1038/nn.4471.

25. Sando $R$, Jiang $X$, Sudhof TC. Latrophilin GPCRs direct synapse specificity by coincident binding of FLRTs and teneurins. Science. 2019;363(6429): eaav7969. https://doi.org/10.1126/science.aav7969.

26. Jo S, Yarishkin O, Hwang YJ, Chun YE, Park M, Woo DH, et al. GABA from reactive astrocytes impairs memory in mouse models of Alzheimer's disease. Nat Med. 2014;20(8):886-96. https://doi.org/10.1038/nm.3639.

27. Wu Z, Guo Z, Gearing M, Chen G. Tonic inhibition in dentate gyrus impairs long-term potentiation and memory in an Alzheimer's [corrected] disease model. Nat Commun. 2014;5(1):4159. https://doi.org/10.1038/ncomms5159.

28. Mele M, Costa RO, Duarte CB. Alterations in GABAA-receptor trafficking and synaptic dysfunction in brain disorders. Front Cell Neurosci. 2019;13:77. https://doi.org/10.3389/fncel.2019.00077.

29. Sieghart W, Savic MM. International Union of Basic and Clinical Pharmacology. CVI: GABAA receptor subtype- and function-selective ligands: key issues in translation to humans. Pharmacol Rev. 2018;70(4):836-78. https://doi.org/10.1124/pr.117.014449.

30. Drasbek KR, Jensen K. THIP, a hypnotic and antinociceptive drug, enhances an extrasynaptic GABAA receptor-mediated conductance in mouse neocortex. Cereb Cortex. 2006;16(8):1134-41. https://doi.org/10.1093/cercor/ bhj055.

31. Zott B, Busche MA, Sperling RA, Konnerth A. What happens with the circuit in Alzheimer's disease in mice and humans? Annu Rev Neurosci. 2018;41(1): 277-97. https://doi.org/10.1146/annurev-neuro-080317-061725.

32. Zott B, Simon MM, Hong W, Unger F, Chen-Engerer HJ, Frosch MP, et al. A vicious cycle of $\beta$ amyloid-dependent neuronal hyperactivation. Science. 2019;365(6453):559-65. https://doi.org/10.1126/science.aay0198.

33. Busche MA, Eichhoff $G$, Adelsberger $H$, Abramowski D, Wiederhold KH, Haass $C$, et al. Clusters of hyperactive neurons near amyloid plaques in a mouse model of Alzheimer's disease. Science. 2008:321(5896):1686-9. https://doi.org/10.1126/science.1162844.

34. Wang Q, Xiao B, Cui S, Song H, Qian Y, Dong L, et al. Triptolide treatment reduces Alzheimer's disease (AD)-like pathology through inhibition of BACE1 in a transgenic mouse model of AD. Dis Model Mech. 2014;7(12): 1385-95. https://doi.org/10.1242/dmm.018218.

35. Zhen J, Qian Y, Weng X, Su W, Zhang J, Cai L, et al. Gamma rhythm low field magnetic stimulation alleviates neuropathologic changes and rescues memory and cognitive impairments in a mouse model of Alzheimer's disease. Alzheimers Dement (N Y). 2017;3(4):487-97. https://doi.org/10.1016/ j.trci.2017.07.002

36. Spires TL, Hyman BT. Neuronal structure is altered by amyloid plaques. Rev Neurosci. 2004;15(4):267-78. https://doi.org/10.1515/REVNEURO.2 004.15.4.267.

37. Tsai J, Grutzendler J, Duff K, Gan WB. Fibrillar amyloid deposition leads to local synaptic abnormalities and breakage of neuronal branches. Nat Neurosci. 2004;7(11):1181-3. https://doi.org/10.1038/nn1335.

38. Limon A, Reyes-Ruiz JM, Miledi R. Loss of functional GABA(A) receptors in the Alzheimer diseased brain. Proc Natl Acad Sci U S A. 2012;109(25):100716. https://doi.org/10.1073/pnas.1204606109.

39. Rice HC, de Malmazet D, Schreurs A, Frere S, Van Molle I, Volkov AN, et al. Secreted amyloid-beta precursor protein functions as a GABABR1a ligand to modulate synaptic transmission. Science. 2019;363(6423):eaao4827. https:// doi.org/10.1126/science.aao4827.

40. Dinamarca MC, Raveh A, Schneider A, Fritzius T, Fruh S, Rem PD, et al. Complex formation of APP with GABAB receptors links axonal trafficking to amyloidogenic processing. Nat Commun. 2019;10(1):1331. https://doi.org/1 0.1038/s41467-019-09164-3.

41. Hijazi S, Heistek TS, Scheltens P, Neumann U, Shimshek DR, Mansvelder HD, et al. Early restoration of parvalbumin interneuron activity prevents memory loss and network hyperexcitability in a mouse model of Alzheimer's disease. Mol Psychiatry. 2020;25:3380-98.

42. Schmid LC, Mittag M, Poll S, Steffen J, Wagner J, Geis HR, et al. Dysfunction of somatostatin-positive interneurons associated with memory deficits in an Alzheimer's disease model. Neuron. 2016;92(1):114-25. https://doi.org/10.101 6/j.neuron.2016.08.034 
43. Ruiter $M$, Herstel $\amalg$, Wierenga $C J$. Reduction of dendritic inhibition in CA1 pyramidal neurons in amyloidosis models of early Alzheimer's disease. J Alzheimers Dis. 2020;78(3):951-64. https://doi.org/10.3233/JAD-200527.

44. Chu DC, Penney JB Jr, Young AB. Quantitative autoradiography of hippocampal GABAB and GABAA receptor changes in Alzheimer's disease. Neurosci Lett. 1987;82(3):246-52. https://doi.org/10.1016/0304-3940(87)902 64-3.

45. Li Y, Sun $\mathrm{H}$, Chen Z, Xu H, Bu G, Zheng H. Implications of GABAergic neurotransmission in Alzheimer's disease. Front Aging Neurosci. 2016;8:31.

46. Zheng J, Li HL, Tian N, Liu F, Wang L, Yin Y, et al. Interneuron accumulation of phosphorylated tau impairs adult hippocampal neurogenesis by suppressing GABAergic transmission. Cell Stem Cell. 2020;26(3):462-6. https://doi.org/10.1016/j.stem.2020.01.021

47. Chandra D, Jia F, Liang J, Peng Z, Suryanarayanan A, Werner DF, et al. GABAA receptor alpha 4 subunits mediate extrasynaptic inhibition in thalamus and dentate gyrus and the action of gaboxadol. Proc Natl Acad Sci U S A. 2006;103(41):15230-5. https://doi.org/10.1073/pnas.0604304103.

\section{Publisher's Note}

Springer Nature remains neutral with regard to jurisdictional claims in published maps and institutional affiliations.

Ready to submit your research? Choose BMC and benefit from:

- fast, convenient online submission

- thorough peer review by experienced researchers in your field

- rapid publication on acceptance

- support for research data, including large and complex data types

- gold Open Access which fosters wider collaboration and increased citations

- maximum visibility for your research: over $100 \mathrm{M}$ website views per year

At $\mathrm{BMC}$, research is always in progress.

Learn more biomedcentral.com/submissions 